\title{
Comportamento Pró-Ambiental de Educandos de Patos, Paraíba, Relacionados aos Resíduos Sólidos
}

\section{Pro-Environmental Behavior of Students from Patos, Paraíba, Related to Solid Waste}

\author{
Deuzeni Maria Silva ${ }^{\mathrm{a}}$; Anna Fernanda Beatriz Amorim Cavalcante ${ }^{\mathrm{b}}$; José Lucas dos Santos Oliveira ${ }^{\mathrm{b}}$ : Edevaldo da Silva*b
}

aUniversidade Federal de Campina Grande. PB, Brasil.

bUniversidade Federal da Paraíba, Programa de Pós-Graduação em Desenvolvimento e Meio Ambiente. PB, Brasil.

*E-mail: edevaldos@yahoo.com.br

\begin{abstract}
Resumo
A poluição ambiental por resíduos sólidos constitui uma problemática ambiental na atualidade, necessitando de uma gestão adequada que estimule a criação de estratégias sustentáveis para minimizar esses impactos, como a inserção da coleta seletiva nos diver sos espaços urbanos e na escola. O estudo teve como objetivo avaliar o comportamento pró-ambiental de educandos do Ensino Médio público de Patos, Paraíba, quanto aos resíduos sólidos. Participaram da pesquisa um total de 352 alunos do Ensino Médio de duas escolas. Os dados foram obtidos por meio da aplicação de um questionário composto por 25 afirmativas no modelo da escala de Likert, cujos níveis de resposta variavam de 1 (concordo totalmente) a 5 (discordo totalmente) e mais três questões discursivas. Os resultados reportaram que os alunos consideram os resíduos sólidos como um grande problema ambiental, considerando que a reciclagem representa uma alternativa para o Desenvolvimento Sustentável. Estes afirmaram que a coleta seletiva deve ser implantada nas cidades brasileiras visando reduzir o volume de resíduos sólidos destinados aos lixões. Além disso, os alunos relataram que a Educação Ambiental deve estar inserida no ambiente escolar tanto na esfera pública quanto privada. As ações de Educação Ambiental desenvolvidas dentro do contexto escolar podem sensibilizar os alunos sobre a importância do uso consciente e descarte adequado dos resíduos sólidos, contribuindo para a sustentabilidade ambiental.
\end{abstract}

Palavras-chave: Educação Ambiental. Escola. Lixo.

\begin{abstract}
Environmental pollution by solid waste is currently an environmental issue, requiring adequate management that encourages the creation of sustainable strategies to minimize these impacts, such as the insertion of selective collection in various urban spaces and at school. The objective of this study was to evaluate the pro-environmental behavior of public high school students in Patos, Paraíba, regarding solid waste. A total of 352 high school students from two schools participated in the study. The data were obtained through the app lication of a questionnaire composed of 25 affirmations in the model of the Likert scale whose levels of response varied from 1 (totally agree) to 5 (totally disagree) and three other discursive questions. The results reported that students consider solid waste as a major environmen tal problem, considering that recycling represents an alternative to Sustainable Development. These confirmed that selective collection should be implanted in Brazilian cities to reduce the volume of solid waste destined to dumps. In addition, students reported that Environmental Education should be embedded in the school environment in both the public and private spheres. The Environmental Education actions developed within the school context can raise the students' awareness regarding the importance of the conscious use and proper disposal of solid waste, contributing to environmental sustainability.
\end{abstract}

Keywords: Environmental Education. School. Trash.

\section{Introdução}

Atualmente o ser humano tem demonstrado maior preocupação com o ambiente, percebendo as questões ambientais como sendo um problema de todos (ROCHA et al., 2015), buscando identificar os fatores que influenciam negativamente na qualidade do ambiente (GAVA; FINOTTI, 2012). Por outro lado, deve-se salientar que tais questões não datam de hoje, ao contrário, vêm acompanhando a evolução da sociedade e estão atrelados às relações culturais, sociais, políticas e econômicas (GONÇALVES; DIAS; MOTA, 2014). A postura adotada pela sociedade em relação a problemática ambiental vem mudando aos poucos, sendo evidenciada pelo aumento das suas discussões. $\mathrm{O}$ atual modo de vida das sociedades humanas indica que é preciso melhorar seu comportamento, valorizando e integrando-se com a natureza na construção de uma relação com mais respeito e equilíbrio (ABRAÃO et al., 2015; VASCONCELOS; SILVA, 2015).

Dentre os problemas ambientais emergentes, pode-se destacar a gestão inadequada dos resíduos sólidos, sendo uma consequência do elevado crescimento populacional, dos seus padrões de consumo, e sobretudo, é impulsionada pelo desenvolvimento econômico e tecnológico (PERUCHIN et al., 2013). No Brasil, a gestão e o gerenciamento de resíduos sólidos urbanos devem ser direcionados pelas seguintes prioridades: não geração, redução, reutilização, reciclagem, tratamento dos resíduos sólidos e disposição final 
ambientalmente adequada dos rejeitos (BRASIL, 2010).

A disposição inadequada dos resíduos sólidos no meio urbano reflete a ausência de responsabilidade social e política em relação ao ambiente (SILVA; LOPES; DANTAS, 2013). Para Santos, Oliveira e Silva (2018), a dificuldade na gestão ocorre por ausência de políticas públicas e ações para processo educativo da sociedade. Nesse sentido, a carência de uma gestão adequada para esses resíduos pode comprometer a saúde e o bem-estar da população (DOMINGOS; BOEIRA, 2015), sendo fonte de riscos à saúde humana (RIBEIRO; RIOS, 2015), além de provocar contaminações ambientais.

Entre as ações ambientais que podem contribuir para a redução desta problemática no ambiente, pôde-se destacar a Educação Ambiental, por representar um processo promissor que busca por meio da sensibilização promover comportamentos ambientalmente adequados nos atores sociais. De acordo com Garcia-Mira; Dumitru e Vega-Marcote (2014), o comportamento pró-ambiental tem como ponto central a preocupação com o ambiente, através do respeito e cuidado, a fim de promover estilos de vida sustentáveis.

A Educação Ambiental deve ser inserida no contexto escolar, pois a escola representa um importante espaço para o processo das transformações psicossociais que por conseguinte desencadearão comportamentos ambientais mais sustentáveis (SILVA; HIGUCHI; FARIAS, 2015). A inserção da Educação Ambiental no processo educativo favorece a construção de comportamentos, habilidades e competências, indispensáveis, para que o indivíduo possa atuar de forma proativa na conservação do ambiente (SILVA et al., 2015).

Assim, as instituições de ensino têm o papel de qualificar e conscientizar os cidadãos, formadores de opinião do futuro (SILVA et. al., 2015), cabendo ao educador, transmitir boas ações, além de estimular a sensibilização dos alunos acerca da importância do ambiente e do uso correto de seus recursos (ABRÃ̃O et al., 2015). Nesse sentido, a escola na qualidade de locus fundamental participa de diversas atividades dentro das políticas públicas de inclusão, as quais visam contribuir para o alargamento das suas funções institucionais (GONÇALVES; DIAS; MOTA, 2014).

Os conteúdos referentes à Educação Ambiental devem ser integrados aos currículos escolares por meio da transversalidade, dessa forma, estes componentes curriculares serão trabalhados nas diversas áreas do conhecimento, abrangendo toda a prática educativa e, ao mesmo tempo, criando uma visão global e abrangente da questão ambiental (BRASIL, 1997).

Em suma, para que mudanças comportamentais realmente aconteçam é preciso desenvolver a Educação Ambiental voltada para a cidadania, despertando nos indivíduos o sentimento de corresponsabilidade e a tomada de atitudes, partindo do princípio que toda a humanidade está ativamente envolvida no quadro atual do ambiente que os cerca, (ABRÃ̃O et al., 2015).
Este estudo teve como objetivo analisar o comportamento pró-ambiental de educandos do ensino médio público de Patos, Paraíba, quanto aos resíduos sólidos.

\section{Material e Métodos}

\section{1 Área de estudo}

O município de Patos está localizado na mesorregião do sertão paraibano, possuindo uma população estimada em 107.067 habitantes e a vegetação que predomina na região é típica do Bioma Caatinga (IBGE, 2019).

Segundo o IDEME (2016), a cidade de Patos está em quinto lugar no ranking do PIB dos municípios paraibanos, registrando uma participação de $2,5 \%$ e um crescimento nominal de $11 \%$, em 2013, tendo como base econômica o setor de serviços.

\subsection{População, amostra e instrumento de coleta de dados}

A pesquisa foi realizada no segundo semestre de 2016, com alunos de Ensino Médio de duas escolas públicas estaduais: Dr. Dionísio da Costa e Auzanir Lacerda, ambas localizadas na cidade de Patos, Paraíba.

Estas escolas estão entre as que apresentam o maior número de alunos matriculados no município, funcionando nos turnos educacionais, de forma variada, e abrangendo alunos de diferentes faixas etárias e de situação econômicasocial.

O tamanho amostral foi determinado de acordo com Rocha (1997), a partir da população de alunos matriculados no Ensino Médio de cada escola pesquisada e considerando um erro padrão de $10 \%$, sendo definidos os seguintes tamanhos amostrais: Escola Auzanir Lacerda (matriculados $=495$; amostra $=210$ ) e Escola Dionísio da Costa (matriculados = 235; amostra =142), totalizando 352 alunos participantes da pesquisa. Os alunos foram selecionados de forma aleatória e casual.

A abordagem dessa pesquisa apresenta natureza qualiquantitativa. Com o intuito de investigar o comportamento pró-ambiental dos alunos relacionado aos resíduos sólidos, foi aplicado um questionário constituído por 25 afirmativas no modelo da escala de Likert (Tabela 1) e mais três (03) questões discursivas, a saber: 1. O que você acha da Educação Ambiental? Por quê?; 2. Exemplifique estilos de vida sustentáveis; 3 . Cite atitudes que você acredita serem boas para reduzir a geração de resíduos sólidos urbanos. As questões em Likert tiveram cinco níveis de resposta, variando de 1 (concordo totalmente) a 5 (discordo totalmente). Para responder os questionários, os alunos utilizaram até 45 minutos, sendo exigido total individualidade por parte destes quanto as suas respostas.

\subsection{Análise dos dados}

Os dados foram analisados por meio da estatística descritiva utilizando o MS Excel 2016. As comparações 
inferenciais entre o perfil dos alunos, entre as escolas e gêneros foram analisadas utilizando o software SPSS v.20, por meio do teste de Mann-Whitney.

\section{Resultados e Discussão}

Dos alunos participantes, 54,7\% $(\mathrm{n}=192)$ foram do gênero feminino e $45,3 \%(n=160)$ do gênero masculino, com idades variando de 14 a 22 anos.

A grande maioria dos alunos $(95,4 \%, \mathrm{n}=335)$ confirmaram que a humanidade é responsável pela problemática ambiental
(Tabela 1), acompanhando a opinião anterior, os entrevistados $(93,4 \%, \mathrm{n}=327)$ se apresentaram conscientes sobre as causas da problemática ambiental ao afirmarem que o modo de vida atual da humanidade deve ser modificado, visando a construção e manutenção de uma relação harmoniosa com o ambiente. Estes dados revelam que, possivelmente, os alunos têm conhecimento sobre a situação caótica que o planeta enfrenta, e sobretudo, conseguem apontar os principais causadores dos problemas ambientais.

Quadro 1 - Frequência percentual das respostas às afirmativas do questionário aplicado aos alunos de duas escolas públicas em Patos, Paraíba

\begin{tabular}{|c|c|c|c|c|c|}
\hline Afirmativas & 1 & 2 & 3 & 4 & 5 \\
\hline i1. Considero que a humanidade é responsável pelos problemas ambientais. & 80,3 & 15,1 & 2,9 & 0,6 & 1,1 \\
\hline $\begin{array}{l}\text { i2. Acredito que o modo de vida da sociedade atual deve ser alterado, visando melhorar } \\
\text { nossarelação com o ambiente. }\end{array}$ & 73,4 & 20,0 & 4,9 & 0,6 & 1,1 \\
\hline i3. Evito o desperdício dos recursos naturais. & 38,0 & 45,5 & 6,3 & 5,1 & 5,1 \\
\hline i4. Colaboro com a conservação ambiental da cidade onde moro. & 30,3 & 48,0 & 7,7 & 5,7 & 8,3 \\
\hline i5. Considero que os resíduos sólidos (lixo) trata-se de um grande problema ambiental. & 71,8 & 16,8 & 4,8 & 3,4 & 3,1 \\
\hline i6. Separo os resíduos sólidos conforme seu tipo. & 27,5 & 28,1 & 8,6 & 13,8 & 22,1 \\
\hline i7. Evito aumentar a geração de resíduos sólidos nos ambientes que frequento. & 39,1 & 33,1 & 9,7 & 9,2 & 8,9 \\
\hline i8. Prefiro sempre usar copos descartáveis, ao invés dos copos reutilizáveis. & 16,8 & 21,7 & 12,0 & 14,0 & 35,6 \\
\hline i9. Acredito que a reciclagem constitui uma opção para o Desenvolvimento Sustentável. & 70,5 & 18,1 & 4,8 & 2,3 & 4,3 \\
\hline i10. Jogo todo tipo de resíduo sólido em qualquer lixeira. & 24,8 & 26,8 & 8,7 & 14,3 & 25,4 \\
\hline $\begin{array}{l}\text { i11. Acredito que os lixões resolvem de forma efetiva o problema dos resíduos sólidos } \\
\text { urbanos. }\end{array}$ & 10,3 & 24,6 & 16,2 & 16,0 & 32,9 \\
\hline i12. Providencio lixeiras específicas para cada tipo de resíduo sólido em minha casa & 16,0 & 12,8 & 11,7 & 16,8 & 42,7 \\
\hline i13. Quando não encontro lixeira por perto jogo qualquer tipo de resíduo sólido no chão. & 18,5 & 20,8 & 12,9 & 8,8 & 39,0 \\
\hline i14. Evito jogar papel no chão. & 48,7 & 25,9 & 5,8 & 8,8 & 10,8 \\
\hline $\begin{array}{l}\text { i15 Acredito que a geração de resíduos sólidos causa prejuízos ambientais, sociais e } \\
\text { sanitários. }\end{array}$ & 66,1 & 20,2 & 4,3 & 5,7 & 3,7 \\
\hline $\begin{array}{l}\text { i16. Sempre faço compras (shopping, supermercados, perfumarias...) } \\
\text { independentemente de estar precisando. }\end{array}$ & 22,5 & 22,8 & 11,1 & 12,3 & 31,3 \\
\hline i17. Descarto rapidamente um material após seu primeiro uso. & 11,7 & 26,2 & 11,7 & 18,2 & 32,2 \\
\hline $\begin{array}{l}\text { i18. Reciclar materiais como papel, plástico e alumínio é uma fonte de economia para a } \\
\text { indústria. }\end{array}$ & 64,7 & 21,4 & 8,0 & 3,6 & 2,3 \\
\hline i19. O aumento do consumismo reduz a disponibilidade dos recursos naturais. & 41,7 & 28,9 & 10,9 & 6,9 & 11,7 \\
\hline $\begin{array}{l}\text { i20. Acredito que a Educação Ambiental deve estar inserida de modo transversal nas } \\
\text { escolas públicas e privadas. }\end{array}$ & 65,1 & 16,0 & 7,4 & 3,5 & 8,0 \\
\hline i21. Permaneço por pouco tempo com o mesmo aparelho de celular. & 15,7 & 10,3 & 11,6 & 13,7 & 48,7 \\
\hline $\begin{array}{l}\text { i22. Acredito que a disposição dos resíduos sólidos em lixões não representa nenhum } \\
\text { risco para o ambiente. }\end{array}$ & 5,2 & 10,6 & 12,4 & 11,2 & 60,6 \\
\hline $\begin{array}{l}\text { i23. Os serviços de coleta seletiva devem ser implementados nas cidades brasileiras } \\
\text { como uma forma de reduzir os volumes de resíduos sólidos destinados aos lixões. }\end{array}$ & 73,8 & 14,8 & 5,7 & 2,0 & 3,7 \\
\hline $\begin{array}{l}\text { i24. Quando faço compras ou descarto materiais recicláveis não me preocupo com os } \\
\text { problemas ambientais gerados. }\end{array}$ & 14,5 & 25,4 & 10,3 & 14,8 & 35,0 \\
\hline $\begin{array}{l}\text { i25. Acredito que o desenvolvimento econômico e tecnológico é limitado dentro } \\
\text { daquilo quepode ser suportado pela natureza. }\end{array}$ & 31,1 & 28,8 & 18,8 & 7,5 & 13,8 \\
\hline
\end{tabular}

1: Concordo totalmente; 2: Concordo em grande parte; 3: Indiferente ou não concorda nem discorda; 4: Discorda em grande parte; 5 Discordo completamente.

Fonte: dados da pesquisa.

Com relação as ações que minimizam a problemática ambiental, apenas 43,6\% $(n=153)$ dos alunos asseguraram que compram só o que precisa, enquanto, $39,9 \%(\mathrm{n}=140)$ destes não se preocupam com os problemas ambientais gerados em função do ato de fazer comprar ou descartar materiais descartáveis. Diante do presente cenário ambiental

se torna- essencial que a humanidade realize em seu cotidiano ações (por mais simples que se constitua) que contribuam com a conservação do ambiente, uma vez que o comportamento do ser humano afeta as condições ambientais.

Nesta perspectiva, é de suma importância a reflexão contínua sobre as diversas práticas socioambientais e, 
sobretudo, o reconhecimento e a mudança de hábitos inadequados sob o ponto de vista ambiental. Com relação ao hábito de fazer compras, este pode estar diretamente relacionado às condições socioeconômicas dos entrevistados. Dos alunos participantes, 83,5\% $(n=292)$ afirmaram que evitam o desperdício dos recursos naturais. Nesta perspectiva, $49,6 \%$ ( $n=174)$ do alunado optam em fazer uso de copos reutilizáveis, embora, 38,5\% $(\mathrm{n}=135)$ ainda adotem o uso de copos descartáveis em suas práticas diárias. Com relação ao consumismo, 70,6\% $(\mathrm{n}=247)$ dos alunos afirmaram que o aumento do consumismo reduz a disponibilidade dos recursos naturais, este dado pôde ser constatado, pelo fato de que, apenas 26,0\% ( $\mathrm{n}=91)$ dos alunos permanecem por pouco tempo com o mesmo aparelho celular, além disso, 78,3\% $(\mathrm{n}=$ 276) afirmaram colaborar com a conservação ambiental da cidade na qual moram.

Estes resultados indicam que, presumivelmente, os alunos conseguem compreender a importância de conservar a natureza, realizando ações que resultam em cuidado com o ambiente, entretanto, algumas práticas ambientalmente corretas ainda são deixadas de lado no cotidiano destes. Com relação ao descarte de copos descartáveis no ambiente escolar, Ribeiro e Rios (2015) relataram que uma das práticas adotadas pela escola para minimizar os impactos causados por esta prática foi a proposta de cada aluno trazer sua própria garrafa de água, podendo enchê-la no bebedouro do refeitório. Machado, Monteiro e Alves (2013) reportaram que, dos alunos participantes da pesquisa de escolas públicas de Ouro Preto, Minas Gerais, 43,0\% acreditam que estudar temáticas ambientais é importante para salvar o planeta; nesse sentido, as instituições de ensino têm o papel de qualificar e conscientizar os cidadãos, formadores de opinião mais crítica e reflexive (SILVA et. al., 2015).

O incentivo para comprar bens e produtos que estão em tendência no mercado-consumista é bastante intensificado pelos meios de comunicação, por isso, o consumismo está fortemente inserido na vida da sociedade contemporânea, porém, infelizmente, os fabricantes e/ou a mídia não relatam os graves problemas ambientais, que estão por trás desta prática, pois visa-se unicamente o lucro financeiro ignorando- se as questões ambientais.

O consumismo, na maioria das situações, é incentivado pelo marketing e pela prática mercadológica que criam significados externos para os objetos por meio da propaganda e publicidade, que por sua vez, exercem seus papéis com perfeição, ao transmitirem a ideia de que 'comprar' é um ato necessário (CORDEIRO et al., 2013). Por outro lado, é válido considerar que os meios de comunicação são importantes, pois realizam a disseminação de informações sobre as questões ambientais. Nesse sentido, Machado, Monteiro e Alves (2013) constataram que $48,0 \%$ dos alunos abordados em sua pesquisa, afirmaram que a televisão é o melhor meio de comunicação para informar sobre temas ambientais, enquanto que, $38,0 \%$ citaram a internet e apenas $14,0 \%$ asseguraram que se informam por meio de revistas.

Os alunos $(88,6 \%, \mathrm{n}=311)$ consideraram que os resíduos sólidos correspondem a um grande problema ambiental, além disso, 86,3\% $(n=303)$ destes reconheceram que a geração de resíduos sólidos pode causar prejuízos ambientais, sociais e sanitários. O aumento da geração dos resíduos sólidos afeta, negativamente, o ambiente, intensificando a problemática ambiental, nesta perspectiva, é indispensável a sensibilização da humanidade quanto a aquisição de medidas e/ou ações que promovam a redução na geração destes.

Além da geração ininterrupta, os resíduos sólidos urbanos apresentam uma precária gestão que resulta de fatores relacionados à sua origem e produção, com a ausência de responsabilidade em relação ao ambiente, sendo impulsionada pela ideia de que os recursos existentes são inesgotáveis (SILVA; LOPES; DANTAS, 2013).

Diante da necessidade de uma normatização para a gestão dos resíduos sólidos e da quantidade progressiva de resíduos gerada no Brasil, desenvolveu-se a Política Nacional de Resíduos Sólidos (WALDMAN, 2013), sendo composta por normas importantes que auxiliam o país no enfrentamento dos problemas ambientais, sociais e econômicos decorrentes do manejo inadequado dos resíduos sólidos, tais como: prevenção e redução da geração dos resíduos, criação de metas para extinção dos lixões, responsabilidade compartilhada dos geradores de resíduos e a inclusão da logística reversa dos resíduos (PATIAS; LISZBINSKI; GOMES, 2015).

No tocante aos resíduos sólidos, é importante desenvolver atitudes solidárias e coletivas embasadas na redução do consumo e do descarte, na escolha de produtos com embalagens menos poluidoras, na valorização daquilo que se adquire e no cuidado com a sua conservação (SILVA; LOPES; DANTAS, 2013).

Constatou-se que $35,9 \%(n=125)$ do alunado afirmaram que não separam o lixo de suas residências conforme o tipo, enquanto que, $51,6 \%$, $(n=181)$ dos mesmos asseguraram que não realizam o descarte correto dos resíduos sólidos nos variados tipos de lixeiras. Além disso, 34,9\% $(n=122)$ dos alunos afirmaram que os lixões resolvem, de forma efetiva, o problema dos resíduos sólidos urbanos, porém, apenas 15,8\% ( $n=55)$ destes reportaram que a disposição de resíduos sólidos em lixões não representa nenhum risco para o ambiente, por outro lado, para $88,6 \%(n=311)$ dos mesmos, os serviços de coleta seletiva devem ser implantados nas cidades brasileiras como uma forma de reduzir os volumes dos resíduos sólidos destinados aos lixões e como alternativa para alcançar o Desenvolvimento Sustentável.

Estes dados sugerem que algumas práticas pro-ambientais ainda não fazem parte da rotina da população (inclusive dos alunos), além disso, apesar do fácil acesso às mais variadas fontes de informações sobre os efeitos prejudiciais que o descarte incorreto dos resíduos sólidos provoca no ambiente, possivelmente, os alunos ainda não se sensibilizaram diante desta problemática e continuam realizando ações 
ambientalmente incorretas. Partindo do princípio de que a produção de resíduos sólidos pela sociedade é inevitável e/ ou ininterrupta, Patias; Liszbinski e Gomes (2015) ressaltam que de um problema individual, o lixo se transforma em um problema público, a partir do momento em que vai para a lixeira, para as ruas ou para os terrenos baldios.

Com relação à mudança de comportamento em relação ao lixo Silva; Lopes e Dantas (2013) verificaram que 90,0\% dos alunos estenderiam seus novos comportamentos não só para o ambiente escolar, mas também para outros lugares como, por exemplo, em suas residências e na rua. Ribeiro e Rios (2015) ratificam que a falta de conhecimento em separar os resíduos sólidos em seus respectivos coletores resulta na disposição dos mesmos em locais inapropriados, aumentando o volume dos resíduos a serem transportados e do volume dos aterros sanitários, consequentemente, diminuindo o tempo de atividade deste sistema de disposição de resíduos.

Em decorrência do descarte incorreto dos resíduos sólidos, o lixão ainda é a principal alternativa de gestão dos resíduos sólidos encontrada na maioria das cidades brasileiras, porém, esta opção resulta em dois tipos de problemas: o ambiental, refletido na contaminação dos rios, do solo, da água e o social, quando os seres humanos por falta de opções socioeconômicas, vivem da coleta de lixo e da busca por algo aproveitável, seja para a venda ou mesmo para alimentação (PATIAS; LISZBINSKI; GOMES, 2015).

Uma outra alternativa de gestão dos resíduos sólidos é a implementação dos serviços de coleta seletiva, pois além de promover ações de reciclagem, valorizando os resíduos descartados, também reduzem os volumes enviados para os aterros (PASCHOALIN FILHO et. al., 2014). Moreira et. al. (2012) constataram que 53,0\% dos alunos conhecem conceitos relacionados ao lixo, mais precisamente, a reciclagem e a coleta seletiva, porém, desconhecem a forma de implantação, vantagens empregatícias, rendas e melhorias de vida resultantes destas alternativas, corroborando com Silva, Lopes e Dantas (2013) ao verificarem que apenas 0,68\% dos alunos do $6^{\circ}$ ano ainda não tinham ouvido falar sobre coleta seletiva do lixo.

Sobretudo, é essencial a manutenção de cuidados com o ambiente. Silva, Lopes e Dantas (2013) destacam ainda algumas formas de cuidado que podem ser adotadas, entre estas, reusar ou reaproveitar os produtos que ainda podem ter alguma utilidade, reagir de forma consciente ao desperdício, escolher produtos sem embalagens ou com embalagens biodegradáveis, e jogar o lixo no lugar certo.

Foi verificado que 50,4\% $(n=177)$ dos alunos se mostraram contrários ao descarte de um material após seu primeiro uso e $72,2 \%(\mathrm{n}=253)$ destes evita aumentar a geração de resíduos sólidos nos locais que frequentam. Estes resultados merecem atenção, visto que o descarte prematuro de materiais reflete o possível esgotamento dos recursos naturais, o aumento da geração de resíduos sólidos e, consequentemente, a intensificação da problemática ambiental.

Neste contexto, Silva, Lopes e Dantas (2013) evidenciam a existência da tendência natural de expansão da industrialização sendo justificada pela produção de bens e consumo e de alimentos em maior quantidade, gerando, consequentemente, volumes proporcionais de resíduos sólidos, que se não forem tratados de forma correta, resultarão em um risco significativo para a degradação da biosfera; uma vez que os resíduos sólidos contêm em sua composição, substâncias que representam riscos para a saúde humana e para o ambiente (CAMPOS et al., 2014), ocasionados pelo acúmulo de dejetos que provocam mau cheiro, atraem organismos transmissores de doenças (RIBEIRO; RIOS, 2015), comprometendo a saúde e o bem-estar da população (DOMINGOS; BOEIRA, 2015).

Com relação à reciclagem, os alunos $(88,6 \%, \mathrm{n}=309)$ afirmaram que esta prática representa uma opção para o Desenvolvimento Sustentável e 86,1\% (n = 302) destes asseguraram que reciclar materiais como papel, plástico e alumínio é uma fonte de economia para a indústria. Tornase nítido que, certamente, os alunos consideram a reciclagem como uma forma viável para amenizar as questões ambientais relacionadas a geração dos resíduos sólidos, além de contribuir, para o bem-estar do planeta, da humanidade e representar uma fonte de renda socioeconômica.

De acordo com Patias, Liszbinski e Gomes (2015), o reaproveitamento da matéria-prima em reciclagem promove uma possível solução para no mínimo três questões fundamentais: a ambiental, a social e a econômica, sendo estas consideradas como problemas comuns de cidades de médio e grande porte, além disso, a reciclagem promove um caminho para o desenvolvimento sustentável; uma vez que consiste em uma alternativa social e econômica para a diminuição da concentração de milhões de toneladas de lixo produzida diariamente nas grandes cidades espalhadas pelo mundo (SILVA; LOPES; DANTAS, 2013). Chao et al. (2015) verificaram que dos idosos participantes de atividades de aventura em sua pesquisa $41,7 \%$ concordaram, e $25,0 \%$ concordaram muito, que a economia de dinheiro é um dos melhores resultados sobre a reciclagem (se mostrando mais antropocêntrico).

Com relação ao descarte de papel, 74,6\% $(\mathrm{n}=262)$ dos alunos afirmaram que evita jogar este tipo de resíduo sólido no chão; 39,3\% ( $\mathrm{n}=140)$ afirmaram que quando não encontram lixeiras por perto jogam qualquer tipo de resíduo sólido no chão, enquanto que, 59,5\% $(n=209)$ dos alunos reportaram que não providenciam lixeiras especificas para cada tipo de resíduo sólido em suas residências. Diante do exposto, pôde-se presumir que os alunos sabem distinguir quais ações e/ou atitudes são prejudiciais ao ambiente, entretanto, isto não é suficiente para que eles assumam atitudes mais ambientalmente corretas, como a que foi supracitada quanto ao descarte de resíduos no chão. A produção de lixeiras, utilizando materiais que seriam descartados, representa uma 
prática simples e viável, porém, esta não é desenvolvida pelos estudantes.

Moreira et al. (2012) verificaram que o item escolar mais desperdiçado pelos alunos participantes da pesquisa são os papéis $(63,0 \%)$. Portanto, torna-se importante a implantação da coleta seletiva nas escolas, para que os resíduos produzidos possam ser descartados de uma forma ambientalmente correta. É importante ainda que a escola promova mudanças de comportamento pessoal, de atitudes e valores de cidadania a fim de contribuir para a formação de cidadãos conscientes, aptos para decidirem e atuarem na realidade socioambiental do planeta (BRASIL, 1997).

Nesta perspectiva, Silva, Lopes e Dantas (2013) asseguraram que oficinas que abordam o reaproveitando de materiais que perderam utilidade para a sua função original, representa uma prática em que os alunos conseguem exercitar sua criatividade, produzindo muitos objetos úteis para a própria escola, para a comunidade e para a população carente do entorno. De acordo com Machado, Monteiro e Alves (2013) o ato de preservar os ambientes naturais está mais relacionado ao comportamento das pessoas do que à presença da humanidade no ecossistema.

Foi verificado que apenas $31,1 \%(\mathrm{n}=109)$ dos alunos concordam totalmente que o desenvolvimento econômico e tecnológico é limitado pela disponibilidade dos recursos naturais. É possível que os alunos não consigam identificar a relação existente entre a natureza e o desenvolvimento do "mundo globalizado", pois diante do esgotamento dos recursos naturais a produção de bens de consumo e de alimentação também cessa. É importante que estas informações sejam esclarecidas para os estudantes com objetivo de promover nos mesmos mudanças comportamentais voltadas para o cuidado ambiental.

Naturalmente, todo o avanço industrial tende a exigir mais do que a natureza pode oferecer, resultando na exploração predatória de recursos naturais e gerando resíduos danosos ao ambiente, caracterizando-se, ainda, pela demanda e pela necessidade de consumo de bens, matéria-prima e os demais artifícios que são indispensáveis para que esse acelerado campo competitivo possa se manter no mercado de trabalho (MOREIRA et. al., 2012).

Beck e Pereira (2012) ressaltam que as soluções efetivas para os atuais problemas ambientais somente poderão ser alcançadas quando a humanidade se libertar dos interesses econômicos e egoístas e, sobretudo, utilizar os recursos tecnológicos para consolidar sistemas sustentáveis de produção e consumo.

Com relação à inserção da Educação Ambiental no espaço escolar, $81,1 \%(\mathrm{n}=284)$ dos alunos afirmaram que esta deve estar inserida de modo transversal tanto nas escolas públicas quanto nas privadas. Este dado representa a realidade da maioria das escolas brasileiras, considerando que, apesar da grande importância da Educação Ambiental no cenário escolar, esta área temática ainda não está sendo abordada de forma significativa pelos professores e gestores escolares, consequentemente, os alunos não possuem meios de incorporar ao seu cotidiano atitudes de conservação ambiental.

Nesta perspectiva, Machado, Monteiro e Alves (2013) verificaram que $51,0 \%$ dos alunos consideram a Educação Ambiental como meio de transformação da sociedade, promovendo melhorias de condição vida tanto de forma individual quanto coletiva. Quando à Educação Ambiental é trabalhada de forma interdisciplinar, o professor tem o importante papel de proporcionar aos alunos situações que lhes permitem construir seu próprio conhecimento, relacionando-o com outros conteúdos curriculares, e sobretudo, promovendo ações interdisciplinares entre os componentes afins (CAVALCANTE, 2016). Por outro lado, Filgueira e Tavarayama (2014) ressaltam a importância de professores preparados para desenvolver a Educação Ambiental nas salas de aula, reduzindo a prática do ensino tradicional de ministrar somente conteúdos como biologia e ecologia, passando a trabalhar questões próximas da realidade dos alunos, sensibilizando-os quanto às questões ambientais e agindo de acordo com a realidade da escola em que atua.

Machado, Monteiro e Alves (2013) constataram ainda que $62,5 \%$ dos alunos informaram que o tema Meio Ambiente está sendo inserido em poucas disciplinas da escola, enquanto que, 25,0\% disseram que o tema é abordado na maioria das disciplinas. Esse resultado revela que a inserção da Educação Ambiental de modo transversal nas escolas ocorre de forma gradativa e consideravelmente lenta. A Educação Ambiental deve ser promovida no universo escolar para que as questões ambientais sejam tratadas com maior abrangência, abrindo espaço para os diversos estudos que se fizerem necessários e, sobretudo, buscando estimular a consciência ambiental nos alunos e desenvolver o senso crítico destes (FILGUEIRA; TAVARAYAMA, 2014).

De modo geral, a interferência humana no ambiente está diretamente relacionada à própria condição de vida dos indivíduos, porém, a forma como se pratica essa interferência é preocupante, por isso, a Educação Ambiental deve ser considerada como um processo que pode melhorar a relação do homem com seu habitat (DUARTE et al., 2015).

Nos dias atuais, é de suma importância ter cuidado ambiental, seja de forma individual ou coletiva, portanto, cabe a educação dar o primeiro passo por meio da conscientização, orientando o aluno sobre as contribuições que ele pode exercer perante a sociedade, mostrando-lhe inicialmente como evitar ou amenizar os prejuízos ambientais (MOREIRA et. al., 2012).

Para adquirir efetivamente a sensibilização ambiental, é necessário que a sociedade tenha um contato contínuo com práticas embasadas no cuidado com o ambiente, não se limitando apenas à aquisição de competências teóricas e de forma pontual (ROSA; CARVALHINHO, 2012), pois com o avanço da Educação Ambiental fortalece ações efetivas no desencadear do comportamento pró-ambiental no ser humano 
(CHAO et. al., 2015).

\section{Conclusão}

Os alunos entrevistados tendem a atribuir à humanidade as causas da degradação ambiental, entretanto, boa parte ainda não incorpora no cotidiano práticas que visem redução do desperdício no uso dos recursos naturais.

Os resíduos sólidos têm sido considerados um dos principais problemas ambientais, apesar de a grande maioria não separar o lixo de acordo com os tipos de coletores. A reciclagem foi considerada importante para promover o desenvolvimento sustentável, e os lixões, para os alunos não representam uma solução para as problemáticas provenientes da presença do lixo nos centros urbanos.

Diante disso, os alunos ainda carecem de atitudes mais sustentáveis, que visem preservação e conservação ambiental, a partir de ações desenvolvidas no âmbito escolar e na sociedade. A ausência de comportamentos pró-ambientais resulta em graves prejuízos ambientais e é fundamental que estas atitudes sejam despertadas precocemente na humanidade.

\section{Referências}

ABRAÃO, S.A. et al. A educação ambiental trabalhada no colégio estadual Anita Grandi Salmon, Sengés - Paraná. Rev. Univ. Vale Rio Verde, v.13, n.1, p.722-734, 2015. doi: http:// dx.doi.org/10.5892/ruvrd.v13i1.2192.

BECK, C.G.; PEREIRA, R.C.F. Preocupação ambiental e consumo consciente: os meus, os seus e os nossos interesses. Rev. Gest. Ambient. Sustentabil., v.1, n.2, p.51-78, 2012. doi: https:// doi.org/10.5585/geas.v1i2.22.

BRASIL. Ministério da Educação. PCN. Parâmetros Curriculares Nacionais - PCN: Meio Ambiente, Saúde. Secretaria de Educação Fundamenta. Brasília: MEC, 1997.

BRASIL. Presidência da República. Lei nº 12.305 , de 02 de agosto de 2010. Política Nacional de Resíduos Sólidos. Disponível em:<http:// http://www.planalto.gov.br/ccivil_03/_ato20072010/2010/lei/112305.htm.htm>. Acessado em: 22 ago. 2020.

CAMPOS, F.A. et al. Avaliação do conhecimento dos profissionais do bloco cirúrgico quanto ao gerenciamento dos resíduos sólidos em saúde. Rev. Visa Debate, v.2, n.1, p.33-38, 2014. doi: https:// doi.org/10.3395/vd.v2i1.97.

CAVALCANTE, M.B. Percepção ambiental sobre os resíduos sólidos: relato de experiência na educação básica. In: EL-DEIR, S.G.; AGUIAR, W.J.; PINHEIRO, S.M.G. Educação Ambiental na Gestão dos Resíduos Sólidos. Recife: Grupo Gestão Ambiental de Pernambuco, Gampe/UFRPE, 2016. p.8-17.

CHAO, C.H.N. et al. Atividades de aventura na natureza e desenvolvimento do comportamento pró-ambiental: análise comparativa entre idosos e condutores. Movimento, v.21, n.1, p.169-180, 2015. doi: https://doi.org/10.22456/1982-8918.46491.

CORDEIRO, A.T. et al. Consumidora consciente?! Paradoxos do discurso do consumo sustentável de moda. Remark, v.12, n.3, p.1-22, 2013. doi: http://dx.doi.org/10.5585/remark.v12i3.2413.

DOMINGOS, D.C.; BOEIRA, S.L. Gerenciamento de resíduos sólidos urbanos domiciliares: análise do atual cenário no município de Florianópolis. Rev. Gest. Ambient. Sustentabilidade, v.4, n.3, p.14-30, 2015. doi: https://doi.org/10.5585/geas.v4i3.275.

DUARTE, R.G. et al. Educação Ambiental na convivência com o semiárido: ações desenvolvidas pela secretaria de educação do estado do Ceará. Rev. Gest. Ambient. Sustentabilidade, v.4, n.1, p.17-29, 2015. doi: https://doi.org/10.5585/geas.v4i1.123.

FILGUEIRA, A.M.F.; TAVARAYAMA, R. Desenvolvimento da educação ambiental no contexto escolar. Nucleus, v.11, n.2, p.147-160, 2014. doi: https://doi.org/10.3738/1982.2278.1050.

GARCIA-MIRA, R.; DUMITRU, A.C.; VEGA-MARCOTE, P. Consumo sostenible en organizaciones: enfoques multimétodo para estudiar la conducta proambientalen lugares de trabajo. Psico, v.45, n.3, p.350-358, 2014.

GAVA, T.; FINOTTI, A. R. Resíduos sólidos urbanos na rede de drenagem da bacia hidrográfica do rio do meio, Florianópolis/SC. Rev. Gest. Ambient. Sustentabil., v.1, n.2, p.79-101, 2012.

GONÇALVES, A.C.G.; DIAS, C.M.S.; MOTA, M.R.A. Alargamento das funções da escola: educação ambiental e sustentabilidade. Educ. Temát. Digit, v.16, n.3, p.551-569, 2014. doi: https://doi.org/10.20396/etd.v16i3.1314.

IBGE. Instituto Brasileiro de Geografia e Estatística. 2019. Disponível em: <http://www.ibge.gov.br/home/> Acesso em: 5 maio 2020.

IDEME. Instituto de Desenvolvimento Municipal e Estadual. 2016. Disponível em: 〈http://ideme.pb.gov.br/>. Acesso em: 29 ago. 2020.

MACHADO, S.F.; MONTEIRO, J.C.L.; ALVES, K.S. Educação Ambiental como promotora de consciência ambiental na rede pública de ensino de Ouro Preto (MG). RBEcotur, v.6, n.1, p.233254, 2013. doi: https://doi.org/10.34024/rbecotur.2013.v6.6291

MOREIRA, G. et al. A conscientização ambiental no âmbito escolar In: CONGRESSO QUÍMICO DO BRASIL. 2012, NatalRN.

PASCHOALIN FILHO, J.A. et al. Comparação entre as massas de resíduos sólidos urbanos coletadas na cidade de São Paulo por meio de coleta seletiva e domiciliar. Rev. Gest. Ambient. Sustentabilidade, n.3. v.3, p.19-33, 2014. doi: https://doi. org/10.5585/geas.v3i3.208.

PATIAS, T.Z; LISZBINSKI, B.B.; GOMES, C.M. A gestão sustentável dos resíduos sólidos em Caxias do Sul-RS. Diálogo, n.28, p.125-146, 2015. doi: http://dx.doi.org/10.18316/1737.

PERUCHIN, B. et al. Gestão de resíduos sólidos em restaurante escola. Tecno-Lógica, v.17, n.1, p.13-23, 2013.

RIBEIRO, A.C.P.; RIOS, E.S. Análise dos resíduos sólidos e alternativas para minimizar seus efeitos em uma unidade de ensino de jovens e adultos do Rio de Janeiro. Rev. SUSTINERE, v.3, n.1, p.65-79, 2015. doi: https://doi.org/10.12957/ sustinere.2015.17329.

ROCHA, I.V. et al. Meio Ambiente: na prática pedagógica do professor do ensino básico do município de Brejo dos Santos-PB. Rev. Univ. Vale Rio Verde, v.13, n.2, p.475-482, 2015. doi: http:// dx.doi.org/10.5892/ruvrd.v13i2.2402.

ROCHA, J.S.M. Manual Projetos Ambientais. Santa Maria: UFSM, 1997.

ROSA, P.F.; CARVALHINHO, L.A.D. A educação ambiental e o desporto na natureza: uma reflexão crítica sobre os novos paradigmas da educação ambiental e o potencial do desporto como metodologia de ensino. Movimento, v.18, n.3, p.259-280, 2012. doi: https://doi.org/10.22456/1982-8918.27564

SILVA, C.O; LOPES, J.P.; DANTAS, M.I. Coleta seletiva e reciclagem do lixo: experiência de educação socioambiental em uma escola da rede estadual de ensino de Maceió, Alagoas. Nature and Conservation, v.6, n.2, p.26-42, 2013. doi: https://doi. org/10.6008/ESS2318-2881.2013.002.0004 
SILVA, D. et al. Influências da preocupação ambiental e do ceticismo frente à propaganda no consumo de produtos verdes. Remark, v.14, n.4, p.529-544, 2015. doi: http://dx.doi. org/10.5585/remark.v14i4.3155

SILVA, W.G.; HIGUCHI, M.I.G.; FARIAS, M.S.M. Educação ambiental na formação psicossocial dos jovens. Ciênc. Educ., v.21, n.4, p.1031-1047, 2015. doi: http://dx.doi.org/10.1590/1516731320150040015

SANTOS, T.M.M.; OLIVEIRA, J.L.S.; SILVA, E. Vulnerabilidade hídrica no Nordeste brasileiro: entre a urbanização e a Educação
Ambiental. Rev. Eletr. Mestr. Educ. Amb., v.35 n.3, p.184-199, 2018. doi: https://doi.org/10.14295/remea.v35i3.8206

VASCONCELOS, H.D.L.; SILVA, E. Research in Environmental Education in the state of Paraíba, Brazil: analysis of its insertion and professors' commitment in post-graduate courses. RevBEA, v.10, p.113-125, 2015. doi: https://doi.org/10.34024/revbea.2015. v10.2054

WALDMAN, M. Lixo domiciliar brasileiro: modelos de gestão e impactos ambientais. Bol. Goiano Geogr., v.33, n.2, p.169-184, 2013. doi: http://dx.doi.org/10.5216/bgg.v33i2.25553. 